\title{
PRESSURE MONITORING DEVICE FOR LOW PRESSURE CUFFS ON TRACHEOSTOMY TUBES
}

\author{
ARThUR A. SCOTT, M.D., F.R.C.P.(c) ${ }^{*}$
}

A GREAT DEAL OF WORK has appeared in the literature in recent years describing the problems occurring at the interface between the ventilator and the patient and describing the damage to the larynx and tracheostomy of those patients requiring long term respiratory support. Pearson and Andrews ${ }^{1}$ have described the incidence and pathogensis of tracheal injury following ventilation using a cuffed tracheostomy tube. Grillo and Cooper ${ }^{2}$ described the development of a low pressure cuff for tracheostomy tubes, designed to minimize tracheal injury. These latter authors used a pressure recording device to measure the intra-cuff pressure

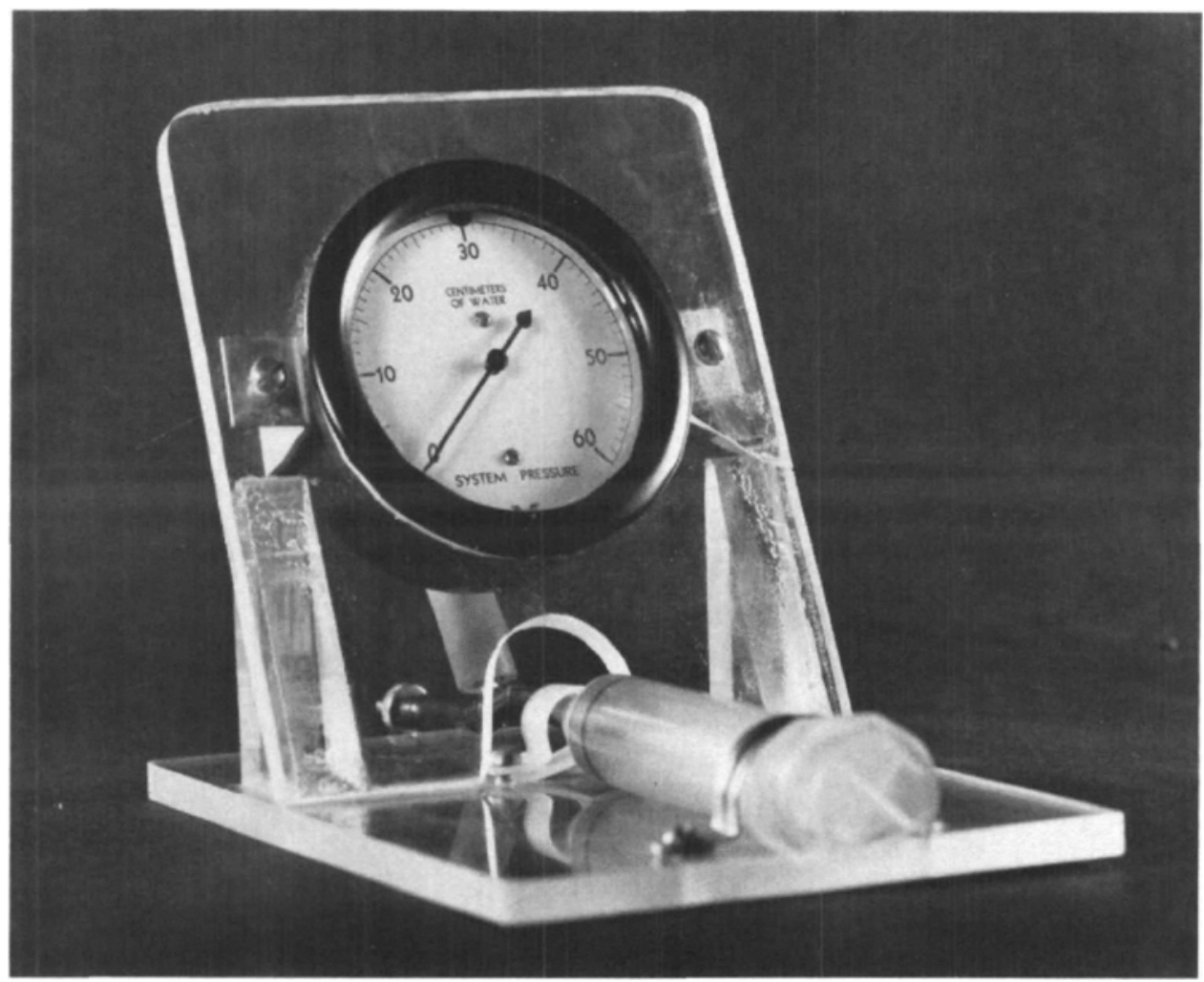

-Respiratory Failure Unit, Toronto General Hospital, and Department of Anaesthesia, University of Toronto.

Canad. Anaesth. Soc. J., vol. 21, no. 1, January 1974 


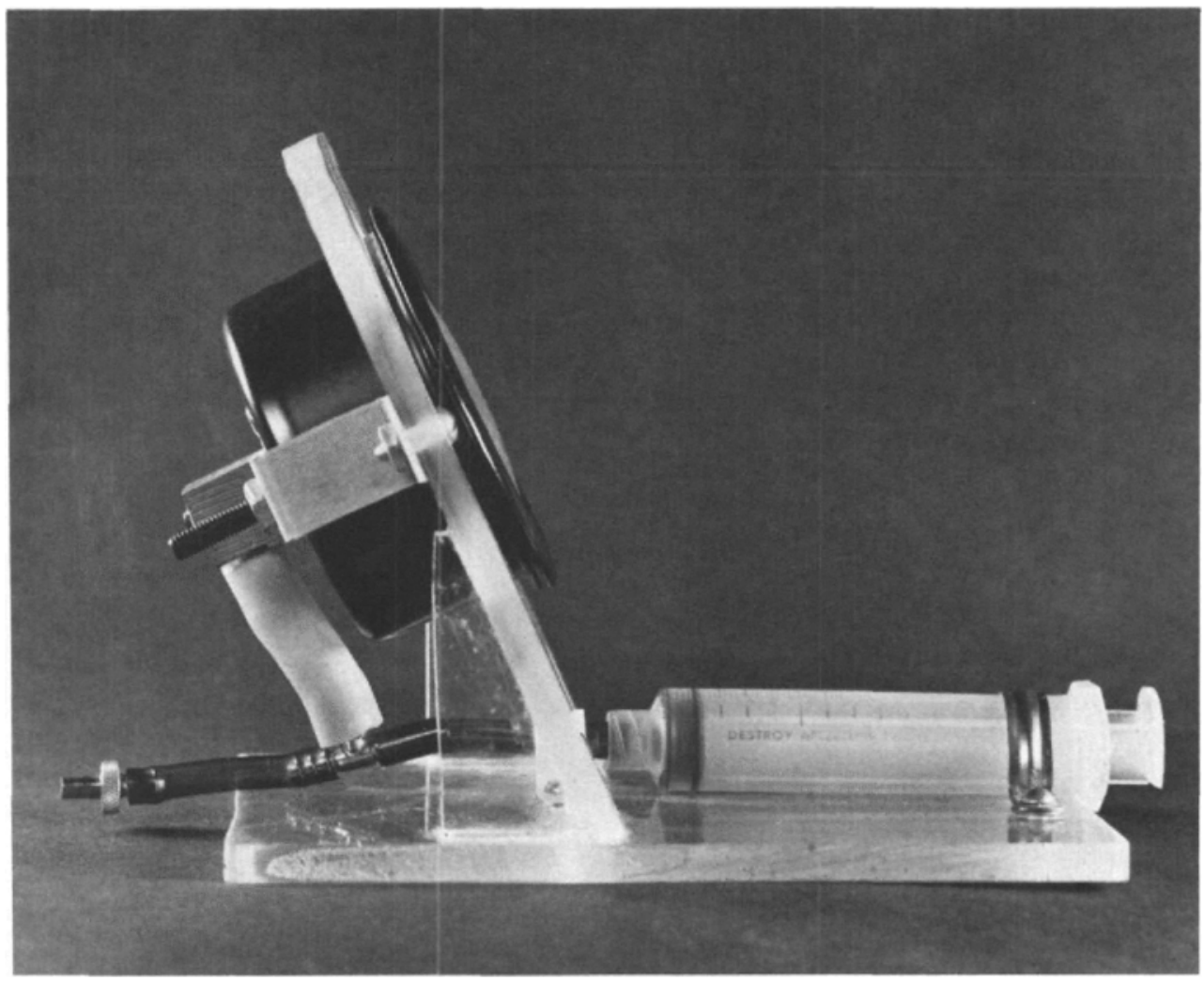

in small standard cuffs and in the large low pressure "floppy" cuffs. They found that the average pressure was $270 \mathrm{mmHg}$ in the small cuffs and $28 \mathrm{~cm} \mathrm{H}_{2} \mathrm{O}$ in the large cuffs.

In the Respiratory Failure Unit at the Toronto General Hospital we are now using a large "floppy" low pressure Forregar cuff on a metal tracheostomy tube. It had been our practice to have the nurse listen over the trachea with a stethescope, while inflating the cuff, until there was no evidence of a leak as indicated by the sound of escaping air. It became apparent, however, that the use of even $1 \mathrm{cc}$ of air more than necessary to prevent a leak resulted in a sharp rise in the intra-cuff pressure, often to pressures exceeding the capillary filling pressures of tracheal mucosa.

In an attempt to find the minimum amount of air which would provide a seal, the simple device illustrated in the figures was developed. The dial is calibrated in $\mathrm{cm} \mathrm{H}_{2} \mathrm{O}$ pressure and the nurse uses this system when inflating the cuff. When the amount of air required to produce a seal is less than that required to distend the cuff $(<10 \mathrm{cc}$ air) the intra-cuff pressure will be an approximation of that applied to the tracheal mucosa. Should the pressure exceed $50 \mathrm{~cm} \mathrm{H}_{2} \mathrm{O}$ pressure the nurse can then remove a small amount of air and often will still be able to 
maintain a seal. If a leak develops the decision can then be made either to accept the leak, compensate for it with the ventilator and accept the attendant risks of aspiration or to use the amount of air required to produce a seal and run the attendant risks of producing mucosal ulceration.

The pressures required to inflate the cuff are recorded on the chart along with the volumes necessary to produce a seal. These data can then be correlated at a later date with evidence of damage to mucosa at the time of extubation. This simple and relatively inexpensive system has permitted our nurses to be more accurate in gauging the amount of air required to produce a seal and has made it possible to venitlate patients satisfactorily with minimal pressure applied to the trachea mucosa by the cuff.

\section{ACKNOWLEDGMENT}

We acknowledge the efforts of Mr. Murray Huntley, R.R.T.(C), Senior Hyperbaric Controller, Toronto General Hospital, in the design and manufacture of the original equipment.

\section{REFERENCES}

1. Andrews, M.J. \& Pearson, F.G. Incidence and pathogenesis of Tracheal Injury following cuffed tube tracheostomy with assisted ventilation. Annals of Surg. Vol. 173, No. 2, Feb. 1971, p. 249.

2. Grillo, H.C. \& Coopen, J.D. A low-pressure cuff for tracheostomy tubes to minimize tracheal injury. J. of Thoracic and Cardiovascular Surgery, Vol. 62, No. 6, p. 898, Dec. 1971. 